\title{
From SOFA to LOUCH: Lexical contributions to pseudoword pronunciation
}

\author{
MARY BETH ROSSON \\ Thomas J. Watson Research Center, Yorktown Heights, New York 10598
}

\begin{abstract}
A word can be pronounced by applying spelling-sound correspondence rules or by looking up its pronunciation in the lexicon. In contrast, a novel string with no lexical entry should be pronounceable only through rule application. Recent research, though, suggests that lexical information may contribute to the pronunciation of nonwords (Glushko, 1979; Marcel, 1980). The present three experiments tested this possibility with the logic of spreading activation. Experiment 1 found a decrease in naming latencies for target words preceded by either related words or pseudowords created from those words, implicating lexical activity in pseudoword pronunciation. In Experiment 2, words visually similar to target pseudowords were semantically primed prior to pseudoword presentation, but the expected facilitation in pseudoword naming did not appear. Experiment 3 provided strong support for the hypothesis, however, demonstrating a marked bias in the pronunciation chosen for an ambiguous pseudoword as the result of priming a visually similar word.
\end{abstract}

An impressive component of a fluent reader's performance is his or her effortless pronunciation of novel words. When presented with a novel string like VADE, most adult readers can immediately produce an acceptable pronunciation. In fact, Theios and Muise (1977) have calculated that fluent readers take only about $20 \mathrm{msec}$ longer to read aloud nonwords like VADE than to read familiar words in their reading vocabulary. This behavior is possible because of the alphabetic nature of written English: Our written and spoken languages contain a number of correspondences between letters or letter groups and sounds (see Venezky, 1972, for a comprehensive discussion of these correspondences). Because of these regularities, most strings have a modal pronunciation. The fact that good readers can usually produce this pronunciation seems to indicate that they have access to information about spelling-sound correspondences.

In the past, most researchers have assumed that readers make direct use of spelling-sound rules when faced with pronounceable nonwords, or pseudowords (e.g., Baron \& Strawson, 1976; Forster \& Chambers, 1973; Frederiksen \& Kroll, 1976; Gough \& Cosky, 1977). There has been some controversy about the unit of rule application; arguments have been made for "spelling patterns" (Gibson, Shurcliff, \& Yonas, 1970), syllables (Spoehr \& Smith, 1973), and letters (Gough

The research reported here was conducted while the author was a predoctoral fellow at the Center for Cognitive Science at the University of Texas at Austin, with the support of a grant from the Alfred P. Sloan Foundation. The author wishes to thank Don Foss and Phil Gough, as well as two anonymous reviewers, for comments on earlier versions of the paper. Requests for reprints should be sent to Mary Beth Rosson, Watson Research Center, P.O. Box 218, Yorktown Heights, New York 10598.
\& Cosky, 1977). However, there has been general agreement among these researchers that rules operating on units of some size are available and that it is these rules that are used to generate phonological representations of novel strings. In fact, readers' ability to pronounce such strings has often been taken as prima facie evidence for the existence and use of rules, as this behavior represents a clear case of generalization to new instances.

The assumption that nonwords are pronounceable only with reference to a set of abstract rules is typically embodied in a "dual process" account of pronunciation (see, e.g., Forster \& Chambers, 1973). In such an account, most familiar words enjoy two options for pronunciation: The reader can engage in lexical access and retrieve the word's pronunciation from a lexical representation, or he can apply an independent set of correspondence rules. In contrast, nonwords are pronounceable only through the latter method, as they have no lexical representation. This dual process model has been used to account for a variety of results over the years, including the pronunciation advantage of both words over nonwords and regular words (those that follow the rules) over exception words (Baron \& Strawson, 1976; Gough \& Cosky, 1977), individual differences in reading aloud (Baron \& Strawson, 1976), and differences in acquired dyslexia (Marshall \& Newcombe, 1973). More recently, though, this traditional view has been challenged (Glushko, 1979, 1981; Marcel, 1980), with the heart of the challenge being a rejection of the need for an independent set of rules.

Marcel (1980) has questioned the adequacy of dual process accounts of acquired dyslexia. He has focused on the type of dyslexia referred to as surface dyslexia: symptomatized by errors related primarily to the spellingto-sound characteristics of the word and by compre. hension that appears to be based on readers' oral 
responses to words. A dual process account attributes this syndrome to an inability of the affected individual to access lexical information directly from print, as well as a lesser impairment in the rule application process (Marshall \& Newcombe, 1973). Marcel rejects this account, though, based on his analysis of reading data collected from patients with the syndrome: He argues that there is considerable evidence of lexical involvement, both with respect to the syntactic and frequency classes of the correct and error responses observed, and in the nature of the spelling-related errors produced. His alternative account proposes that all strings, both words and nonwords, are pronounced with reference to lexical representations. The key assumption here is that both the visual and phonological representations of known words are segmentable. As a result, not only can they be retrieved as whole entities when lexical items are encountered, but also they can be used in the segmentation and synthesis of phonemes necessary to pronounce novel strings. A natural consequence of such a model is that the phonology assigned to segments of a novel string will be affected by the lexical properties of words that include the same segments.

A similar proposal has been made by Glushko (1979, 1981). In his view, any string, regardless of lexical status, activates a multitude of stored orthographic forms and their corresponding phonological associations. A synthesis process is then assumed to integrate all of this available information to produce an appropriate pronunciation response. The critical point is simply that both words and nonwords are pronounced with reference to the same store of information, eliminating any need for a separate body of rules to be used in the pronunciation of novel strings. Glushko offers few details about the mechanics of the activation and synthesis processes (see Rumelhart \& McClelland, 1981, for a discussion of how such an activation and synthesis process might work), but it seems that a necessary assumption is one made explicit by Marcel (1980): The word-specific orthographic and phonological information must be segmentable, if novel combinations are to be possible.

Glushko $(1979,1981)$ reports experimental evidence in support of his proposal. His major finding involves a reanalysis of the word regularity effect, in which words that follow the rules of English pronunciation are observed to have shorter pronunciation latencies than exception words that break the rules (Baron \& Strawson, 1976; Gough \& Cosky, 1977). Dual process models attribute the finding to the usefulness of both wordspecific associations and rule knowledge in generating a regular word's pronunciation, but only the former for an exception word. However, Glushko argues that the regularity effect is more accurately characterized as a consistency effect, in that regular words are simply those words most likely to activate consistent phonological representations. So, for example, a regular word like BEET is assumed to activate not only its own lexical representation, but also those of orthographic "neighbors" (e.g., FEET, MEET); the key is that these additional sources of activation bear consistent pronunciation information. Similarly, an exception word like BEEN activates itself and its neighbors (e.g., SEEN, TEEN); here, however, the additional sources of activation provide conflicting phonological information. The argument is that the competing information interferes with production of the correct response, causing increased latencies. Glushko argues that while dual process models predict longer latencies for exception words (e.g., BEEN), they cannot account for the similar disadvantage he has found for their regular word (SEEN) and pseudoword (REEN) counterparts.

Notice, though, that Glushko's $(1979,1981)$ dismissal of dual process models is based on a definition of "rule" that assumes only one phonological correspondence for a given letter or letter group. If, on the other hand, multiple correspondences for some visual strings are allowed (ordered, perhaps, by frequency of occurrence), then a dual process model might also predict a consistency effect in pseudoword naming times. That is, Glushko's results do not necessitate a conclusion of lexical involvement in pseudoword naming; competition among alternative spelling-sound correspondences could produce the same effects. Glushko (1979, p. 686) admits to this possibility himself. However, he comments that this account would require such a proliferation of rules that the original reason for proposing their existence, cognitive economy, would be lost, and the resulting model would be very difficult to distinguish from the activation model he proposes.

Glushko's comments are apropos. It certainly becomes difficult to maintain a division between "correspondence rules" and "word-specific associations" when one allows for the existence of the competing multiletter rules necessary to explain Glushko's $(1979,1981)$ data. And, given Marcel's (1980) analysis of readers with surface dyslexia, one might be tempted to conclude that readers' ability to pronounce novel words with reference to known ones has been amply demonstrated. However, such a conclusion is too hasty. While Marcel's analysis is intriguing, it is based on clinical protocols. As a result, it is not as systematic as an experimental demonstration, and it is difficult to know to what extent the data are a function of response biases and strategies engendered by the patients' reading problems. At this point, there is still a need for experimental verification of the claim that pseudowords are pronounced with reference to lexical representations.

The present work was designed to assist in this verification. The experiments were based on the assumption that if a given lexical item is activated during pronunciation of a visually similar pseudoword, then one should be able to observe consequences of that activation, as well as to promote the likelihood that the information activated will contribute to the pronunciation process. 


\section{EXPERIMENT 1}

A common finding in psycholinguistic research is that the processing of a given word facilitates subsequent processing of semantically related words (e.g., Meyer, Schvaneveldt, \& Ruddy, 1975; Neely, 1977). So, for example, presentation of the word BREAD in a lexical decision task speeds decisions for a related word like BUTTER occurring next in the list. The mechanism generally postulated to account for these findings is one of spreading activation: The activation at a particular lexical site during processing of that item spreads to related items in the lexicon. The resulting facilitation seems to be quite short-lived (see, e.g., Gough, Alford, \& Holley-Wilcox, 1979), but for related words occurring next to each other in a word list, the effect is quite reliable.

The present experiment applied semantic priming logic to the detection of lexical activation during pronunciation of nonlexical items (i.e., pseudowords). The reasoning was as follows: If a known word is activated in the process of pronouncing a pseudoword (e.g., if LAMB is activated during the pronunciation of FAMB), then its activation should be measureable. One way to detect it is by measuring facilitation in the processing of related words (e.g., SHEEP); this facilitation is predicted by spreading activation theories of semantic priming. An alternative detection method would be to simply follow the pseudoword with the activated word itself, expecting to see a reduction in its naming latency. This method was rejected, however, as facilitation observed in such a situation could be at least partly attributable to processes other than phonological conversion: It is quite likely that preceding LAMB with FAMB could prime visual encoding and articulatory processes as well as phonological assignment. The indirect method offered by semantic priming enables a more confident conclusion that activation has occurred at a specific lexical site, as the connection between the lexical model and the target is purely semantic. Thus, during the experiment, subjects pronounced target words (SHEEP) immediately after pronouncing pseudowords created from words semantically related to the targets (FAMB) or not (FURE). The hypothesis was that the pseudowords would cause activation of their neighbors during pronunciation and that this activation would spread to the targets, facilitating their pronunciation. The word priming condition (SHEEP preceded by either LAMB or LURE) was included for comparison purposes.

\section{Method}

Subjects. Forty-one undergraduate students from an introductory psychology class served as subjects in the experiment. Their participation was in fulfillment of a class requirement. All subjects were native English speakers and had normal or corrected-to-normal sight and hearing.

Stimuli. Forty word pairs were obtained by selecting stimulusresponse pairs from word association norms (Riegel, Note 1; Russell \& Jenkins, Note 2). An attempt was made to choose stimulus words whose spellings were unique, such that no single letter could be substituted for the initial consonant to create another word (e.g., LAMB-SHEEP). In a few cases, a single other word could be made, but it was of very low frequency. These word pairs, then, constituted the related-word prime condition. To form the related-pseudoword condition, single consonants were substituted for the stimulus words' initial consonants (e.g., FAMB; for words that began with a consonant cluster, like $\mathrm{TH}$, another consonant that would form a similar cluster, like $\mathrm{C}$, was chosen). The control word primes were generated by finding words that matched each related-word prime in initial letter, length, and approximate frequency (e.g., LURE). The initial consonant was replaced by the same consonant used in generating the related pseudoword to create the pseudoword control (e.g., FURE). In all, then, there were four priming conditions: related word (LAMB-SHEEP), "related" pseudoword (FAMB-SHEEP), unrelated word (LURE-SHEEP), and "unrelated" pseudoword (FURE-SHEEP).

Four stimulus lists were constructed, so that 10 target words appeared in each priming condition in a given list and all targets appeared in all conditions across lists. The experimental pairs were inserted in random order into lists containing 40 filler words and 40 filler pseudowords. The inclusion of filler stimuli and the decision to structure the stimuli as a continuous pronunciation list rather than as prime-target pairs were intended to reduce subjects' awareness of the experimental manipulation and any conscious expectancies concerning the target words that might result. A fixed list of 22 practice words and pseudowords was appended to the beginning of each list, resulting in complete lists of 182 items.

Procedure. The items to be named were presented one at a time on a display scope controlled by a PDP-8/1 computer; the computer also collected articulation onset latencies by means of a throat microphone. Subjects' pronunciations were monitored by the experimenter, and any errors were transcribed for later analysis.

Subjects were run individually. They were given instructions to name each item in the list as quickly and accurately as possible; they were warned of the presence of pseudowords. Presentation of the list began when the subject pressed a foot pedal. Each stimulus item remained on the display screen until it was named. A variable interstimulus interval of $500-1,000 \mathrm{msec}$ elapsed between items in the list. The subject was free to take a break at any time. Few subjects chose to do this, however, as the entire list took only about 4 or $5 \mathrm{~min}$ to name.

\section{Results and Discussion}

Mean naming latencies for the target in the four prime conditions are presented in Table 1 , as well as the

Table 1

Naming Latencies (in Milliseconds) and Errors (in Percentages) for Primes and Target Words in Experiment 1

\begin{tabular}{llccr}
\hline & & $\begin{array}{c}\text { Average Prime } \\
\text { Latency }\end{array}$ & $\begin{array}{c}\text { Average Target } \\
\text { Latency }\end{array}$ & Errors \\
\hline Related Word & LAMB-SHEEP & 622.0 & 577.2 & 2.2 \\
Unrelated Word & LURE-SHEEP & 630.2 & 594.6 & 5.3 \\
Related Pseudoword & FAMB-SHEEP & 788.8 & 606.2 & 12.3 \\
Unrelated Pseudoword & FURE-SHEEP & 792.8 & 618.5 & 9.4 \\
\hline
\end{tabular}


error rates for each condition. Latencies greater than a criterion value 2.5 standard deviations beyond any subject's grand mean have been replaced with that value. Trials on which errors occurred have been discarded. In scoring the data, trials were counted as errors if the target or the prime was mispronounced. Errors on the prime composed over $90 \%$ of the total errors, with the majority of these occurring on the pseudoword primes.

Mean latencies served as dependent measures in two analyses of variance, one using latencies averaged across items and the second collapsing across subjects. For both analyses, word list was the single between-groups factor; the lexical status and semantic relatedness of the prime served as repeated-measure factors. The results of the two analyses were combined (after Clark, 1973) to compute the $\min \mathrm{F}^{\prime}$ statistic, allowing simultaneous generalization across subjects and items. This analysis revealed a significant effect of lexical status $\left[\mathrm{min} \mathrm{F}^{\prime}(1,72)\right.$ $=12.04, p<.01]$; target naming was faster if it was preceded by a word rather than a pseudoword. There was also an effect of semantic relatedness $\left[\mathrm{min} \mathrm{F}^{\prime}(1,59)\right.$ $=4.26, \mathrm{p}<.05]$; target naming was speeded by presen tation of a semantically related prime. Planned comparisons revealed that the facilitation occurred both for the related-word primes $[\mathrm{t}(37)=3.4, \mathrm{p}<.01]$ and for pseudowords visually similar to those words $[\mathrm{t}(37)=2.4$, $\mathrm{p}<.05]$. The interaction of lexical status and relatedness was not significant $\left[\mathrm{min} \mathrm{F}^{\prime}(1,66)=.17\right.$, n.s.], nor were any effects involving the materials variable.

These data support the hypothesis that pronunciation of a pseudoword includes activation of its orthographic neighbors. The support is provided by a decrease in naming latency for words semantically related to these visually similar words. Because these related words were not presented themselves, the activation must have been the result of pseudoword processing. Of interest is the apparent absence of an interaction between lexical status and relatedness. It is surprising that the activation resulting from the processing of the related word itself does not produce significantly more facilitation than that produced by a pseudoword visually similar to it. However, one must be cautious in interpreting this null result, particularly as the mean difference was in the right direction (the related-word primes produced $5 \mathrm{msec}$ more facilitation than the related-pseudoword primes), and the overall facilitation effect was small. It is possible that the experimental manipulation of relatedness was simply not strong enough to allow detection of an interaction.

The other finding of the experiment, that targets are named more rapidly if preceded by a word than a pseudoword, was not explicitly predicted. However, it is certainly not surprising. Encountering a pseudoword is an unusual experience and probably carries with it a certain amount of cognitive "overhead." Given the fairly short period between items $(500-1,000 \mathrm{msec})$, subjects may still have been recovering from extra processing evoked by the pseudoword when the target appeared, resulting in longer naming times in those conditions.

This proposal can be examined more rigorously by analyzing the reaction times for the four different types of primes. These data, along with their associated error rates, also appear in Table 1 . A cursory glance at the data suggest that the only differences present are those between words and nonwords. An analysis of variance conducted on the data confirmed this suggestion: The only effect even approaching significance was the wordnonword classification $[F(1,40)=159.52, p<.0001]$. Notice that this analysis also argues against an alternative explanation for the relatedness effect in the target latencies: A variable interstimulus interval (between $500-1,000 \mathrm{msec}$ ) was in effect for prime-target pairs in all conditions. Thus, if the related primes had by chance been easier to pronounce, one might argue that their apparent facilitation for the targets was a simple consequence of providing subjects with a functionally longer interstimulus interval. The fact that related and unrelated primes (both words and nonwords) were pronounced equally rapidly serves as evidence against such an argument.

Examination of Table 1 suggests that error rates vary across the four different priming conditions. An analysis of variance performed on mean error rates confirmed this suspicion: Significantly more errors were made for the pseudoword prime conditions $[F(1,37)=44.38$, $p<.0011$. This effect interacted with the relatedness variable, however, with the difference being greater in the related prime condition $[F(1,37)=5.97, p<.02]$. At first glance, this may seem to compromise the interpretation of the latency differences. That is, when error rates vary systematically with experimental manipulations, one immediately fears the presence of varying speed-accuracy tradeoff criteria across conditions. As it turns out, though, such a problem is unlikely to have produced the error patterns seen here. Because a target trial was counted as an error if a mistake was made on either the prime or the target, most of the errors reflected in Table 1 are actually attributable to mispronunciations of the pseudoword primes, not the targets. In fact, the interaction of relatedness with lexical status is the result of four pseudowords in the related condition whose individual error rates were $40 \%$ or more (the items were HADY, BRIEST, KION, and LUSTICE). When the targets primed by these pseudowords were dropped from the analysis, the interaction present for the error data disappeared, but the pattern of results for the latency data remained unchanged.

In summary, this experiment provides some initial support for the notion that pseudoword pronunciation produces activation of visually similar words. Notice, though, that the design of the experiment does not permit the conclusion that activation of orthographic neighbors occurs during the generation of a phonological 
representation for the nonword. It may be that the activation occurs subsequent to the pseudoword pronunciation, perhaps because the sound of the pseudoword "reminds" subjects of the similar word. If so, the pseudoword priming effect observed in this experiment could be epiphenomenal to the pronunciation process itself. The next experiment addresses this issue.

\section{EXPERIMENT 2}

In the first experiment, it was reasoned that if pronunciation of a pseudoword is mediated by visually similar lexical items, then certain consequences of the resulting activation should be observable. But, while the facilitation prediction was supported, it was noted that the activation producing facilitation could have occurred either prior to or subsequent to the pronunciation process. The present experiment was designed to avoid this interpretive problem. It also uses the logic of spreading activation, but it attempts to produce facilitation in the naming of the pseudowords themselves, rather than examining the spread of activation produced as a consequence of pronouncing them. Specifically, the prediction is that if a target pseudoword (DEPPER) is preceded by a word semantically related to one of its orthographic neighbors (SALT), its naming time will be decreased. This should result from the spread of activation from the word prime to the pseudoword's neighbor (PEPPER), making the pronunciation of this similar known word more available.

\section{Method}

Subjects. Participants were 29 undergraduate students fulfilling a course requirement in an introductory psychology class. All subjects were native English speakers and had normal or corrected-to-normal sight and hearing.

Stimuli. To generate the pseudoword targets, 28 words were selected whose spellings following the initial consonant were unique to that word (e.g., PEPPER). Psuedowords were then created from these words by replacing the first letter with another consonant (e.g., DEPPER). No words beginning with consonant clusters were used in this experiment, as the previous one had indicated that these words, when turned into pseudowords, produce considerably longer naming times. Two priming words were then selected for each pseudoword; one semantically related to the word the nonword had been created from (e.g., SALT), and the other unrelated, but matched with the related prime for initial letter, length, number of syllables, and approximate frequency (e.g., SELL). Median frequency (Kuð̌era \& Francis, 1967) of the related primes was 36.5 , and that of the unrelated ones was 30.5 .

Two lists were created such that half of the pseudowords appeared with the related prime in each list and the targets appeared in both primed conditions across lists. The 28 primetarget pairs were inserted in random order into a list of 73 filler words and 73 filler pseudowords. The order of a given target was fixed across the two lists. A list of 18 practice words and pseudowords was appended to each list, producing complete lists of 220 items.

Procedure. The procedure for this experiment was identical to that of Experiment 1. Because the word lists were slightly longer than in the previous experiment, time to name the entire list was greater, averaging about 5 or $6 \mathrm{~min}$.

\section{Results and Discussion}

Mean naming latencies and pronunciation errors for the target pseudowords in both priming conditions are shown in Table 2. Latencies greater than a criterion value 2.5 standard deviations beyond any subject's grand mean have been replaced with that value, and reaction times from error trials have been discarded.

The latencies served as dependent measures in two analyses of variance, one with means calculated across items and a second collapsing across subjects. Neither analysis yielded a significant effect of priming condition $[F(1,27)=1.33$, and $F(1,26)=.10$, respectively $]$. In fact, the only significant effect across either analysis was an interaction of materials with relatedness when the data were analyzed by item $[\mathrm{F}(1,26)=11.82$, $p=.002]$. This effect was due entirely to differences in overall reaction times between the groups of subjects receiving the two different lists; one group was about $50 \mathrm{msec}$ faster than the other, producing an advantage for the item in the condition the faster group received, independent of the prime manipulation. Analyses of error rates also revealed a lack of variation across experimental conditions.

These data fail to provide any support for the hypothesis that lexical information is used to mediate the pronunciation of novel words. If the priming manipulation did accomplish its goal, an increased activation level for the orthographic neighbors of target pseudowords, the pronunciation of the target nonwords should have been facilitated. One possibility, of course, is that the priming manipulation was not successful. The related words may not have produced enough of an increase in activation at the intended lexical sites. This proposition is consistent with the observation that the direction of the difference between the two priming conditions was as expected, with the pseudowords preceded by related primes having a mean latency $8.5 \mathrm{msec}$ greater than that of those preceded by unrelated primes. That the manipulation had some effect is suggested by the fact that in postexperimental interviews, a number of the subjects voiced the spontaneous hypothesis that the relationships present between the related primes and pseudowords in the list comprised at least one experimental manipulation. Perhaps a replication of the experiment with a stronger manipulation would produce the predicted effect.

Notice, though, that even had a significant priming effect occurred, the results would have some ambiguity in interpretation. It is certainly reasonable to expect

Table 2

Naming Latencies (in Milliseconds) and Errors (in Percentages) for Target Pseudowords in Experiment 2

\begin{tabular}{cccc}
\hline \multicolumn{1}{c}{$\begin{array}{c}\text { Example } \\
\text { Prime Type }\end{array}$} & $\begin{array}{c}\text { Average } \\
\text { Latency }\end{array}$ & Errors \\
\hline Related Word & SALT-DEPPER & 675.9 & 7.4 \\
Unrelated Word & SELL-DEPPER & 684.4 & 6.2 \\
\hline
\end{tabular}


acilitation in the phonological translation of a pseudoword due to activation of relevant phonological informaion, but it is also possible that processing facilitation would occur in visual analysis of the pseudoword. That $s$, before any phonological conversion, be it lexical or rule based, can take place, the system must recognize the visual contents of the string. And it is certainly possible that this recognition would be aided by raised activation levels of words of similar visual form (see. e.g., Rumelhart \& McClelland, 1981). This inherent problem in interpreting the latency results led to the adoption of a different approach in the third experiment.

\section{EXPERIMENT 3}

As indicated in the previous section, it became desirable to find a measure independent of the visual processing conducted on a pseudoword string. A more qualitative measure of pronunciation behavior, pronunciation choice, seemed an attractive candidate. Although many novel strings have a single acceptable pronunciation (e.g., FOTE would be acceptable only as / fot/), others have at least two, due to inconsistencies in English spelling. sound correspondences (e.g., BINT might be pronounced either as /bInt/ or as /baynt/). And, given two pronunciation options, it might be possible to bias the choice a reader makes by activating a lexical model supporting one of the choices. If the bias manipulation were successful, it would stand as evidence of a lexical contribution to pronunciation that could not be attributed to visual processing.

In the experiment, subjects pronounced pseudowords whose pronunciations were ambiguous (e.g., LOUCH can be pronounced like COUCH or like TOUCH). The target nonwords were preceded by one of two word primes (e.g., SOFA or FEEL), with the two primes intended to activate lexical models reflecting two possible phonological representations of the ambiguous string. It was expected that although one pronunciation would generally be preferred (the "regular" one), there would be a tendency for readers' selections to be biased by the primed word.

\section{Method}

Subjects. Twenty-two undergraduate students from an introductory psychology class participated in the experiment in partial fulfillment of a course requirement. All subjects were native English speakers with normal sight and hearing.

Stimuli. Twenty-four pairs of words were selected such that the members of each pair represented conflicting pronunciations of the letter string following the initial consonant. For most pairs, there was a clear distinction between the member embodying the "regular" pronunciation (as defined by the rules of Venezky, 1970) and that embodying an exception pronunciation (e.g., COUCH-TOUCH). While some effort was made to equate the frequencies of the regular and exception exemplars across pairs, this proved to be difficult, due to the generally elevated frequency of exception words. As a result, the median frequency for the regular exemplars was 29.5 , and that of the exception words was 87.5. Following selection of these word pairs, a single pseudoword was created to represent each pair of words, by replacing the initial consonant with a new letter (e.g., LOUCH), and a priming word semantically related to each of the source words was selected (e.g., SOFA-FEEL).

Two word lists were created; in each, half of the pseudowords were preceded by primes intended to activate their regular orthographic neighbors, and the other half were preceded by words priming exception neighbors. Each set of 24 prime-target pairs was inserted in random order into lists of 82 filler items, half words and half nonwords. The filler items varied across the two lists.

Procedure. The general procedure followed that of Experiments 1 and 2 . However, in this experiment, subjects were asked to name both lists, in an effort to see if their pronunciation selections would change across lists, in accordance with the prime. The order of list presentation was balanced across subjects, and there was a break of about 2 min between presentation of the first and second lists. As in the other experiments, naming latencies were obtained. The dependent measure of interest was pronunciation choice, though; so extreme care was taken to transcribe the pronunciation for each target pseudoword as it occurred. The only other change in procedure was a slight increase in emphasis on accuracy rather than speed: Subjects were asked to name the word as quickly as they could, but the accuracy of their response was stressed.

\section{Results and Discussion}

As expected, subjects demonstrated a strong tendency to choose the regular pronunciation of the ambiguous pseudowords, selecting these pronunciations over $80 \%$ of the time. In order to detect effects of the prime manipulation, the proportion of regular pronunciations of each target pseudoword was calculated for both the prime condition expected to facilitate that selection and the prime condition expected to prime a competing pronunciation. The means of these proportions are presented in Table 3, broken down by list number. Recall that the same targets appeared in both lists, but in different priming conditions. Thus, the proportions for complementary priming conditions across lists reflect choices for the same items, by the same group of subjects, but under the influence of a different prime. Error percentages are also presented in Table 3 . In this experiment, a more liberal error classification scheme was adopted, due to the ambiguity of the target strings: Any pronunciation reflecting a spelling-sound correspondence represented by at least one lexical model was accepted as a correct response. So, for example, the acceptable pronunciations of VOUR were those that rhymed with FOUR, HOUR, or TOUR, as these represent all relevant lexical models.

The proportion data were submitted to two analyses

Table 3

Proportion (P) of Regular Pronunciation Choices for Ambiguous Pseudowords in Experiment 3

\begin{tabular}{|c|c|c|c|c|c|}
\hline \multirow{2}{*}{$\begin{array}{l}\text { Model } \\
\text { Primed }\end{array}$} & \multirow{2}{*}{$\begin{array}{c}\text { Example } \\
\text { Prime-Target }\end{array}$} & \multicolumn{2}{|c|}{ List 1} & \multicolumn{2}{|c|}{ List 2} \\
\hline & & $\mathbf{P}$ & E & $\mathrm{P}$ & $\mathrm{E}$ \\
\hline Regular & SOFA-LOUCH & .888 & 4.2 & .802 & 6.4 \\
\hline Exception & FEEL-LOUCH & .750 & 6.4 & .814 & 2.7 \\
\hline
\end{tabular}

Note $-E=$ percentage error. 
of variance, one in which the proportions had been calculated across items for a given subject and another collapsing across subjects for a given item. For both analyses, list order was a between-groups factor, with both priming condition and number of lists serving as repeated-measure factors. The results of these analyses were then combined to allow generalization across both random factors. This analysis revealed a significant effect of priming condition $\left[\min F^{\prime}(1,33)=4.36\right.$, $\mathrm{p}<.05]$. Subjects were less likely to choose the regular pronunciation of a pseudoword when a lexical item representing a competing choice had been primed. Interpretation of this main effect must be tempered, however, by the presence of an interaction between priming condition and number of list. Although the interaction effect in the combined analysis was only marginally significant $\left[\min F^{\prime}(1,40)=4.03, .05<p<\right.$ $.10]$, it was significant in both of the separate analyses $[F(1,21)=10.56, p<.004$, for the analysis by subjects; $F(1,22)=6.52, p=.018]$. The biasing effect of the prime was much stronger in the first list a subject received.

An initial examination of Table 3 might lead one to conclude that there was no effect of prime at all in the second list subjects saw. (Recall that the second list presented a subject with the same target words, but with the complementary set of primes.) However, this initial conclusion is inaccurate: Some bias is apparent in a comparison of proportions across lists, in that complete consistency in choices across lists would produce proportions for the second that were the inverse of those for the first. The size of the priming effect in the second list can be assessed by contrasting proportions for the same words across lists. So, for example, the table reports that $88.8 \%$ of the pseudowords whose regular pronunciations were primed in the first list (e.g., SOFA-LOUCH) were given that pronunciation; in contrast, when a competing pronunciation was primed in the second list (e.g., FEELLOUCH), that percentage dropped to 81.4\%. Likewise, when the exception pronunciation was primed in the first list, only $75.0 \%$ of the items were given their regular pronunciation; this percentage jumped to $80.2 \%$ in the second list, when the regular alternative was primed. A posteriori contrasts performed using the Neuman-Keuls procedure indicated that only the former contrast was significant at the .05 level; the latter was marginally significant $(p<.10)$. In general, though, these findings demonstrate that the prime manipulation was strong enough to cause subjects to revise their original pronunciations of some pseudowords.

The decreased effect of the priming manipulation in the second list is not surprising. A number of studies have demonstrated strong effects of recency of presentation (e.g., Scarborough, Cortese, \& Scarborough, 1977): A recently presented item seems to maintain an elevated activation level for some time, to the extent of eliminating the typical effect of word frequency. It seems quite possible that some type of recency phenom. enon was responsible for the reduced biasing effect of the prime in the second list. In fact, it is surprising that any bias at all occurs in the second list, as subjects were asked to rename pseudowords originally named only a few minutes earlier.

Although not the focus of the experiment, an inter. esting question involves the latencies associated with the choice measures. One might hypothesize, for example, that an ambiguous word whose exception pronunciation is primed should be pronounced more slowly than one whose regular pronunciation is primed. By definition (and reflected in the choice data), an ambiguous string's "regular" pronunciation is generally preferred. Hence, priming an alternative to that choice might be expected to interfere with normal processing As the procedure employed automatically collected latency data, this question was easily addressed. Sub. ject means, broken down by type of prime and list number, appear in Table 4. Initial inspection indicates that there are no systematic differences between the two prime conditions, and an analysis of variance supported such a conclusion. The only significant effect was of list number, with latencies decreasing for the second list subjects pronounced $[F(1,21)=9.12, p<.007]$ The lack of an effect of prime type on naming latency is disappointing, but it may be due in part to the increased emphasis on accuracy in the experiment Perhaps if the experiment were run with the more tradi tional emphasis on speed, condition latency differences would obtain.

Error rates were generally low, again probably due to the slightly increased emphasis on accuracy in the instructions. However, analysis of error rates yielded two results. First, there was a significant interaction of priming condition with list order, just as in the choice data $[F(1,20)=6.43, p<.05]$. For the first list, sub. jects made fewer errors when the regular version of the pseudoword was primed; the reverse was true for the second list. This may indicate that items whose excep tion pronunciation had been primed were more likely to generate errors and that these errors tended to carry over to the second list, when the item was re-presentec in the context of the other prime. The second finding was an interaction of list number with list order, the between-groups factor $[F(1,21)=4.85, p<.04]$ : Sub jects in one group made fewer errors on their seconc list, while the other group increased their number of

Table 4

Naming Latencies (in Milliseconds) for Pseudowords in Experiment 3

\begin{tabular}{llll}
$\begin{array}{l}\text { Model } \\
\text { Primed }\end{array}$ & $\begin{array}{c}\text { Example } \\
\text { Prime-Target }\end{array}$ & List 1 & Lis 2 2 \\
\hline Regular & SOF A-LOUCH & 625.9 & 592.7 \\
Exception & FEEL-LOUCH & 624.3 & 602.9 \\
\hline
\end{tabular}


errors. This is probably due to differences between the two lists, with one promoting more errors than the other.

These data provide strong evidence for the involvement of lexical information in pseudoword pronunciation processes. When subjects saw an ambiguous pseudoword for the first time, they generated its regular pronunciation almost $14 \%$ less often if an orthographic neighbor bearing competing information had been semantically primed. Further, the prime manipulation caused readers to change their pronunciation of some items within a span of 5 or $10 \mathrm{~min}$. These two findings indicate that appropriate pronunciations of these strings are by no means preordained. Transient fluctuations in lexical activity appear quite able to affect the phonological representations built for novel words.

\section{GENERAL DISCUSSION}

The three experiments reported in this paper have tested the hypothesis that lexical information can play a role in the pronunciation of words never encountered before. The first experiment produced some support for the claim, although as we have seen, there is an alternative explanation for the pattern of results obtained. The second experiment failed to provide any support at all for the argument. The results of the third experiment, though, offer direct support for the hypothesis, demonstrating that an increase in the activity level of a word visually similar to a pseudoword can influence the pronunciation chosen for the nonword.

Throughout the paper, the phrases "lexical involvement," "lexical contribution," and "lexical mediation" have been used to describe the phenomenon under study. These descriptors are admittedly vague, and at this point, they must remain so. The research reported here does not offer any support for a particular mechanism of lexical involvement in the pronunciation of pseudowords. It simply points to the need for including some such mechanism in any model of pronunciation processes. However, the nature of the results obtained do provide some restraint on the types of mechanisms offered. For instance, the mechanism must be one that predicts a contribution from lexical items differing from the pseudowords in only their first letter. This might be a problem for the model proposed by Marcel (1980), which includes a parser that proceeds from left to right in identifying familiar orthographic forms. Given a strict left-to-right parse, it is difficult to see how BINT might come to be pronounced like PINT; it seems that the parse would first identify the morpheme BIN, resulting in a pronunciation that rhymes with MINT. At this point, Marcel has not precisely specified how a particular morpheme is identified and its phonology is retrieved; perhaps variations in the activation levels of relevant lexical entities can be incorporated into the process.
An important issue, of course, revolves around the types of visual match between a word and a nonword that will result in a contribution from the word. Activation models such as those proposed by Glushko (1979) or Rumelhart and McClelland (1981) seem to predict that contributions will be a function of visual overlap between the stimulus and stored visual forms. There is no provision for greater salience of particular kinds of matches. There is no reason, for instance, to expect GLOOD to be more affected by FLOOD than by GLOOM (assuming the two words are of approximately equal frequency). Both the experiments reported by Glushko and those reported here, though, examined the pronunciation of nonwords bearing a specific type of resemblance to known words: All were created via substitution of an initial consonant. As a result, the new word always rhymed with the word it was created from. One wonders if similar findings woud have obtained if the orthographic mismatch had occurred at some other point in the string. Would information stored with COUCH aid pronunciation of COUSH as much as that of LOUCH? A negative answer to this question would imply that the lexically based mechanism responds selectively to different types of visual match.

While questions concerning the nature of a lexical mechanism in pseudoword pronunciation are interesting and should certainly be pursued in the future, they were not the focus of the present work. The goal was to demonstrate the existence of lexical contributions through the use of indirect semantic priming. And although that demonstration was quite successful, several caveats are in order. First, it has often been argued that the priming manipulations used in word processing experiments (e.g., preceding PEPPER with SALT) are not at all representative of naturally occurring context (see, e.g., Alford, 1980; Forster, 1978; Gough et al., 1979). If so, then the lexically based processes observed here may not take place in normal oral reading. Additional paradigms that do not rely on such a manipulation are needed to provide converging evidence for these effects. Second, the findings need to be extended to nonambiguous pseudowords. In the work reported here, the strongest findings occurred for nonwords having more than one possible pronunciation. Further research is needed to establish the existence of similar processes in the naming of nonwords with a single acceptable pronunciation. And finally, the consequences of different types of visual match need to be examined. As noted above, current work has focused on the contributions of lexical models mismatching only in initial consonant. If this is the only kind of match that can lead to a lexical contribution, the implications become much less interesting, as few novel words we encounter possess this characteristic.

Given the results of Experiment 3 and those of Glushko (1979) and Marcel (1980), it is tempting to conclude that lexical representations are used in pro- 
nouncing any string, novel or familiar, and that the need for a rule-based mechanism independent of the lexicon has been abolished. However, there are clearly many questions left to be answered. It may well be that lexical involvement occurs only in special cases in which the "regular" correspondences do not operate quickly and efficiently; this might explain the lack of a lexical effect in Experiment 2, in which the target pseudowords did reflect regular, unambiguous spelling-sound rules. At this point, though, it is fair to conclude that lexical knowledge can contribute to the phonological representations of novel strings.

\section{REFERENCE NOTES}

1. Riegel, K. F. Free associative responses to the 200 stimuli of the Michigan Restricted Association Norms (Rep. No. 8, NIMH Grant MH 07619-01A1). University of Michigan, 1965.

2. Russell, W. A., \& Jenkins, J. J. The complete Minnesota norms for responses to 100 words from the Kent-Rosanoff Word Association Test (Rep. No. 11, ONR Grant N8 ONR-666216). University of Minnesota, 1954.

\section{REFERENCES}

ALforn, J. A., JR. Lexical and contextual effects on reading time. Unpublished doctoral dissertation, University of Texas, Austin, 1980.

Baron, J., \& Strawson, C. Use of orthographic and word-specific knowledge in reading words aloud. Journal of Experimental Psychology: Human Perception and Performance, 1976, 2, 386393.

Clark, H. H. The language-as-fixed-effect fallacy: A critique of language statistics in psychological research. Journal of Verbal Learning and Verbal Behavior, 1973, 12, 335-359.

Fonste R, K. I. Levels of processing and the structure of the language processor. In W. E. Cooper \& E. Walker (Eds.), Sentence processing: Psycholinguistic studies presented to Merrill Garrett. New York: Erlbaum, 1978.

Fonster, K. I., \& Chambers, S. M. Lexical access and naming time. Journal of Verbal Learning and Verbal Behavior, 1973, 12, 627-63s.

Frederiksen, J. R., \& Kroll, J. Spelling and sound: Approaches to the internal lexicon. Journal of Experimental Psychology: Human Perception and Performance, 1976, 2, 361-379.

Gibson, E. J., Shurcliff, A., \& Yonas, A. Utilization of spelling patterns by deaf and hearing subjects. In $H$. Levin \& J. P. Williams (Eds.), Basic studies in reading. New York: Basic Books, 1970.

GLUSH Ko, R. J. The organization and activation of orthographic knowledge in reading aloud. Journal of Experimental Psychology: Human Perception and Performance, 1979, 5, 674-691.

Glushko, R. J. Principles for pronouncing print: The psychology of phonography. In A. M. Lesgold \& C. A. Perfetti (Eds.), Interactive processes in reading. Hillsdale, N.J: Erlbaum, 1981. Gough, P. B., Alford, J. A., Jr., \& Holley-Wilcox, P. Words and contexts. In M. L. Kamil \& A. J. Moe (Eds.), Reading research: Studies and applications. City, State: Publisher, 1979.

Gough, P. B., \& Cosky, M. J. One second of reading again. In N. J. Castellan, D. B. Pisoni, \& G. R. Potts (Eds.), Cognitive theory (Vol. 2). Hillsdale, N.J: Erlbaum, 1977.

Kučera, H., \& Francis, W. Computational analysis of presentday American English. Providence, R.I: Brown University Press, 1967.

MArcel, T. Surface dyslexia and beginning reading: $A$ revised hypothesis of the pronunciation of print and its impairments. In M. Coltheart \& J. C. Marshall (Eds.), Deep dyslexia. London: Routledge \& Kegan Paul, 1980.

Marshall, J. C., \& Newcombe, F. Patterns of paralexia: A psycholinguistic approach. Journal of Psycholinguistic Research, 1973, 2, 175-199.

Meyer, D. E., Schvaneveldt, R. W., \& Ruddy, M. G. Loci of contextual effects on word recognition. In P. M. A. Rabbitt \& S. Dornic (Eds.), Attention and performance $V$. New York: Academic Press, 1975.

NEELY, J. H. Semantic priming and retrieval from lexical memory: Roles of inhibitionless spreading activation and limited capacity attention. Journal of Experimental Psychology: General, 1977, 106, 226-254.

RumelhaRt, D. E., \& McClelland, J. L. Interactive processing through spreading activation. In A. M. Lesgold \& C. A. Perfetti (Eds.), Interactive processes in reading. Hillsdale, N.J: Erlbaum, 1981.

Scarborough, D., Contese, C., \& Scarborough, H. Frequency and repetition effects in lexical memory. Journal of Experimental Psychology: Human Perception and Performance, 1977, 3, 1-17.

Spoenr, K, T. Phonological encoding in visual word recognition. Journal of Verbal Learning and Verbal Behavior, 1978, 17, 127-142.

Spozhr, K. T., \& Sмiтh, E. E. The role of syllables in perceptual processing. Cognitive Psychology, 1973, 5, 71-89.

Theios, J., \& Muise, G. The word identification process in reading. In N. J. Castellan, Jr., D. B. Pisoni, \& G. R. Potts (Eds.), Cognitive theory (Vol. 2). Hillsdale, N.J: Erlbaum, 1977.

VENEzKy, R. L. The structure of English orthography. The Hague: Mouton, 1970.

(Received for publication December 22, 1981; revision accepted October 10, 1982.) 